\title{
Correction to: Two-Factor Blockchain for Traceability Cacao Supply Chain
}

Andi Arniaty Arsyad, Sajjad Dadkhah, and Mario Köppen

\section{Correction to: \\ Chapter "Two-Factor Blockchain for Traceability Cacao Supply Chain" in: F. Xhafa et al. (Eds.): Advances in Intelligent Networking and Collaborative Systems, LNDECT 23, https://doi.org/10.1007/978-3-319-98557-2_30}

In the original version of the book, typographical error in second author name "Sajjad Dhadkah" should be corrected to read as "Sajjad Dadkhah" in chapter "Two-Factor Blockchain for Traceability Cacao Supply Chain". The correction chapter and the book have been now updated with the change.

The updated online version of this chapter can be found at https://doi.org/10.1007/978-3-319-98557-2_30 